\title{
An international resource for lab animal science
}

The International Council for Laboratory Animal Science (ICLAS) is an international scientific organization located in Brussels, Belgium, and established by the United Nations Educational, Scientific and Cultural Organization in 1956. According to its mission statement, ICLAS has seven aims, which include promoting international cooperation in lab animal science, developing laboratory animal science worldwide, disseminating information in the field, promoting ethical principles and promoting the 3Rs, among others. Its Strategic Plan is to serve as a resource for knowledge in the field, an advocate for advancement of laboratory animal science in developing countries and a source of guidelines and standards in the field. The 'About ICLAS' section includes a 90-page History of the International Council for Laboratory Animal Science, written in 2004, as well as the Council's Constitution.

ICLAS members include countries, laboratory animal science associations, scientific societies, universities and research institutes, organizations with reciprocal relationships, and honorary members, or scientists who are recognized for "distinguished contributions to laboratory animal science (or ICLAS)." A world map highlighting the member countries, organizations and associates is featured on the 'Membership' page. The bulk of the international members are European nations, but laboratory animal science organizations from all over the world are also represented.

The 'Board and Members Area' is not accessible to the public, but much of the 'Committees \& Activities' content is accessible and is quite informative. The 'Regional Programs Funding' page has a document about regional programs and an application for funding of regional programs that are likely to have the greatest influence and audience. The 'Communications Committee' describes the committee's goals, which include producing a periodic ICLAS Bulletin. They recently launched the version of the webpage reviewed here. The 'Education and Training Committee' page discusses the needs for education and training "to promote and harmonize education and training in laboratory animal science, particularly in regions of the world where such opportunities are lacking or few." The site provides links to laboratory research organizations, such as the American College of Laboratory Animal Medicine (ACLAM), the American Association for Laboratory Animal Science (AALAS) and others that are responsible for training.

The ICLAS Scholarship Program for Veterinarians in Laboratory Animal Science and Medicine provides short-term (1-3 years) educational programs for lab animal veterinarians. Such programs are available in Canada, the US, Mexico, India, Spain and Denmark. Scholarships cover two-thirds of the cost; employers or applicants are expected to make up the rest.

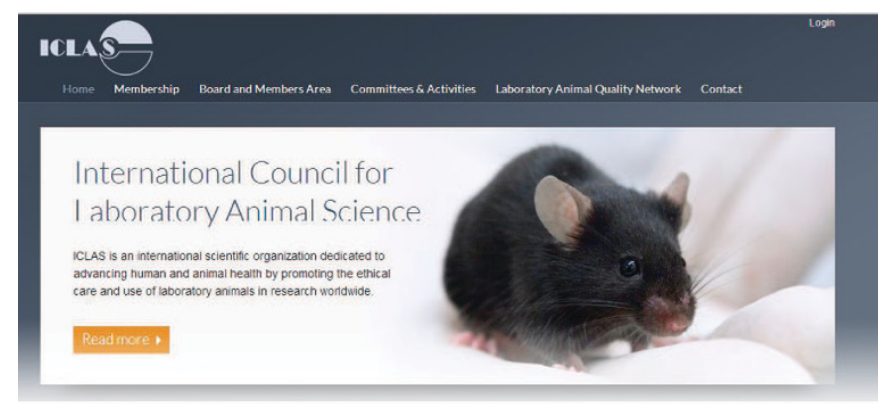

Long lists of training and educational resources are available by region: Asia, India, US, Brazil, Latin America, Germany, Canada, Africa, Europe and Mexico. Educational resources in the US alone form a list that is nine pages long.

Regional Committees promote development of laboratory animal science within specific areas of the world, as their names imply. The webpages for the Asia and Africa Regional Committees are under construction. The Australia \& New Zealand Regional Committee is new and little information about it is available at this time. The Europe Regional Committee offers training fellowshipsthree for 2014-at a host institution for a technician, an animal facility manager/animal welfare officer/veterinarian or a scientist who uses animals in research.

The ICLAS homepage also includes a tab for the 'Laboratory Animal Quality Network,' made up of individuals who are on the governing board of ICLAS and who are "experts from the fields of health monitoring and/or genetics of laboratory animals." This network has two programs: a Performance Evaluation Program for Diagnostic Laboratories and a Genetic Quality Monitoring Program. Laboratories may participate in these programs to improve the health and genetics of their animals.

This is a very easy site to read: other than the homepage and the 'Awards' page, which include photos, it is entirely in text in black and shades of blue, with mustard-yellow highlights.

The content, though not overwhelming in amount, is useful and interesting, particularly for those in management or those who are interested in the scholarships offered. A good many of the documents on the site are downloadable. It's easy to maneuver from page to page. Some pages, such as the awards page, were badly outdated. Overall, it is a good compendium of documents on policy and education, with opportunities for scholarships for additional training.

\section{http://iclas.org}

Content

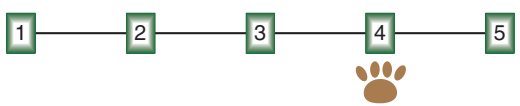

Appearance

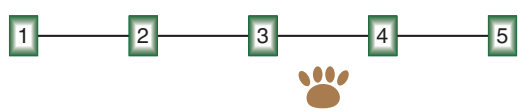

Usability

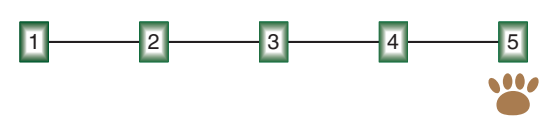

